Int. J. Electrochem. Sci., 14 (2019) $8014-8027$

\title{
Novel Glucose Oxidase Interlocked Prussian Blue/Polysulfone Stereo-Structure and its Application in Amperometric Glucose Biosensor
}

\author{
Cang Wang ${ }^{1}$, Min Pan ${ }^{1}$, Hang Chen ${ }^{1}$, Dajing Chen ${ }^{2, *}$, Yuquan Chen ${ }^{1, *}$ \\ ${ }^{1}$ Department of Biomedical Engineering, Zhejiang University, Hangzhou 310027, China \\ ${ }^{2}$ Medical School, Hangzhou Normal University, Hangzhou, 311121, China \\ *E-mail: djchen@hznu.edu.cn
}

doi: $10.20964 / 2019.08 .51$

Received: 25 March 2019 / Accepted: 21 May 2019 / Published: 30 June 2019

In this study, we present a controllable Prussian Blue (PB)- Polysulfone (PSF) stereo-structure with glucose oxidase (GOD) interlocked for glucose biosensing. This work links the electrochemical catalytic properties of PB with the large surface area and mass transport of three-dimensional macro-porous PSF and highlights the importance of interlocking GOD with PB to improve sensor sensitivity and linearity, which also maintains glucose sensor activity. The prepared PB-PSF-GOD glucose biosensor exhibited a 1-12 mM linear range, high affinity and good selectivity with a low applied potential of $-0.05 \mathrm{~V}$ (vs $\mathrm{Ag} / \mathrm{AgCl}$ ). Furthermore, the prepared sensor only attenuated by $10 \%$ after 7 days of continuous testing. The advanced properties of the novel GOD interlocked PB-PSF structure may have promising applications in enzymatic biosensors, especially the continuous glucose monitoring (CGM).

Keywords: Prussian blue; nanostructure; glucose oxidase; glucose biosensor; nanocoating

\section{FULL TEXT}

(C) 2019 The Authors. Published by ESG (www.electrochemsci.org). This article is an open access article distributed under the terms and conditions of the Creative Commons Attribution license (http://creativecommons.org/licenses/by/4.0/). 